\title{
High Frequency of Mayaro Virus IgM among Febrile Patients, Central Brazil
}

\section{Sandra Brunini, Divânia Dias Silva França, Juliana Brasiel Silva, Leandro Nascimento Silva, Flúvia Pereira Amorim Silva, Mariana Spadoni, Giovanni Rezza}

Author affiliations: Universidade Federal de Goiás, Goiânia, Brazil (S. Brunini); Secretaria Municipal de Saúde, Goiânia (D.D.S. França, J.B. Silva, L.N. Silva, F.P.A. Silva); Universidade Federal do Paraná, Paranà, Brazil (M. Spadoni); Istituto Superiore di Sanità, Rome, Italy (G. Rezza)

DOI: https://dx.doi.org/10.3201/eid2306.160929

Mayaro virus (MAYV), an Aedes mosquito-borne alphavirus, is endemic to Brazil and other South America countries. We investigated dengue- and chikungunya-negative febrile patients visiting rural areas near Goiânia, Goiás, and found a high proportion (55\%) of MAYV IgM. Our findings suggest the presence of highly endemic foci of MAYV in central Brazil.

$\mathrm{M}$ ayaro virus (MAYV) is an Aedes mosquito-borne alphavirus of the New World, transmitted mainly by tree canopy-dwelling Haemagogus spp. mosquitoes, was discovered in Trinidad in 1954. MAYV causes a denguelike acute febrile illness with arthralgic manifestations (1). Exposure to MAYV has been reported in several countries of Central and South America, and Mayaro fever has been identified in French Guiana, Suriname, Venezuela, Peru, Bolivia, and Brazil $(2,3)$. In Brazil, Mayaro fever has been reported in the Amazon region $(2,4)$ and in Mato Grosso $(5,6)$.

At the end of 2014, after chikungunya virus (CHIKV) spread in South America, the Brazil Ministry of Health enhanced the surveillance system for dengue-like illness. Accordingly, febrile patients attending primary care centers are tested for dengue virus (DENV) infection by using viral antigen (NS1), virus isolation, or reverse transcription PCR (up to 5 days after symptom onset), and/or ELISA for IgM (after the sixth day). DENV-negative patients fitting the clinical and epidemiologic criteria for chikungunya set by the Ministry of Health (http://www.saude.gov.br) are notified to the Center for Strategic Information in Health Surveillance of Goiânia city for further investigation.

Blood samples collected during June 1, 2014-June 30, 2015, were stored at $-20^{\circ} \mathrm{C}$ and sent to the Department of Arbovirology and Hemorrhagic Fevers, Instituto Evandro Chagas (Belém, Brazil), to be evaluated for CHIKV by an IgM-capture ELISA (MAC ELISA; Centers for Disease Control and Prevention, Atlanta, GA, USA). A subsample of CHIKV-negative serum collected during December 2014-June 2015 was tested by hemagglutination inhibition (HI) (7) against the most common arboviruses. We evaluated serum samples with monotypical or heterotypic reactivity to alphaviruses, with $\mathrm{HI}$ titers $\geq 40$ using an IgM MAC ELISA for MAYV, as described by Kuno (8) and then modified (9). The results were sent to the Center for Strategic Information in Health Surveillance for further clinical and epidemiologic investigations.

We tested 75 samples from DENV-negative patients for CHIKV. Five of the $31 \mathrm{DENV}$-negative persons from whom serum was collected during June-December 2014 and none of the 44 from January-June 2015 were positive for CHIKV IgM. Two additional samples yielded indeterminate results for CHIKV.

Of 27 CHIKV-negative samples tested by HI, 16 were reactive to alphaviruses (median titer 160 [range $80-1,280])$; of these, $15(56 \%)$ were confirmed as positive by IgM MAC ELISA for MAYV, and 1 sample was borderline. The median interval between symptom onset and serum collection was 37 days (range 12-167 days).

Patients were a median of 45 years of age (range 30-70 years). Fourteen were women. Patients' educational level was high; $11(73 \%)$ patients had $>8$ years' education, and $47 \%$ had $>12$ years' education.

All the patients with an antibody profile suggesting recent MAYV infection resided in Goiânia but had traveled to rural areas in the 15 days before symptom onset. Twelve patients had visited farms or small holdings in the forests around towns located $34 \mathrm{~km}$ (Hidrolandia) and 46 km (Bela Vista) from Goiânia (online Technical Appendix Figure, https://wwwnc.cdc.gov/EID/article/23/6/16-0929Techapp1.pdf). In particular, 7 patients had been around Bela Vista and 5 in the area of Hidrolandia, whereas only 1 had been near Pontalina and 2 in Itacaja (Tocantins), which is outside the state of Goiás. Ten of these 11 patients reported engaging in recreational activities.

The high frequency of MAYV IgM detection among febrile patients in Goiânia is surprising. Identification of recent infections most likely acquired in rural areas and forests around the city of Goiânia indicates the existence of active foci where a sylvatic cycle of MAYV is established. The MAYV belt around Goiânia, where epizootics of jungle yellow fever were also reported (http://www. paho.org/hq/index.php?option $=$ com_docman\&task $=$ doc view\&Itemid $=270 \&$ gid $=34247 \&$ lang $=$ en), is represented by a wet area hosting small primates, which may play a role as virus amplifier.

Our conclusions are subject to several limitations. First, selection bias could affect findings regarding the proportion of MAYV recent infections because of the lack of systematic testing for dengue-like illness. Second, we did not conduct PCR to identify acute infections because 
Table. Clinical characteristics of 15 patients positive for lgM against Mayaro virus, Goiânia, Goiás, Brazil, June 2014June 2015

\begin{tabular}{lc}
\hline Sign or symptom & No. (\%) patients \\
\hline Fever & $15(100)$ \\
Arthralgia & $14(93)$ \\
Joint edema & $14(93)$ \\
Rash & $14(93)$ \\
Headache & $13(87)$ \\
Weakness & $13(87)$ \\
Myalgia & $12(80)$ \\
Eye pain & $8(53)$ \\
Icterus & $4(27)$ \\
Photophobia & $3(20)$ \\
Severe itching & $3(20)$ \\
Lymphadenopathy & $2(13)$ \\
Vomiting & $2(13)$ \\
\hline
\end{tabular}

the samples were collected after the viremic phase. Third, plaque-reduction neutralization testing was not performed, and because of the lack of convalescent serum, IgG seroconversion or titer increase were not evaluated; however, MAC ELISA is considered a valid technique for diagnosing recently acquired infection with MAYV (10). Finally, the frequency of rash (Table), higher than in other case series (4), might be overestimated because of stringent selection criteria used for MAYV testing.

In conclusion, infection with MAYV occurs more frequently than expected in central Brazil. Mayaro fever should be considered in the differential diagnosis with DENV, CHIKV, and Zika virus infections in areas characterized by arbovirus cocirculation.

\section{Acknowledgment}

We thank Lívia Carício Martins for supporting testing activities.

Dr. Brunini is an associate professor at the Faculty of Nursing, Federal University of Goiás. Her primary research interests include infectious disease epidemiology and HIV and sexually transmitted diseases.

\section{References}

1. Anderson CR, Downs WG, Wattley GH, Ahin NW, Reese AA. Mayaro virus: a new human disease agent. II. Isolation from blood of patients in Trinidad, B.W.I. Am J Trop Med Hyg. 1957;6:1012-6.

2. Azevedo RSS, Silva EVP, Carvalho VL, Rodrigues SG, Nunes-Neto JP, Monteiro H, et al. Mayaro fever virus, Brazilian Amazon. Emerg Infect Dis. 2009;15:1830-2. http://dx.doi.org/ 10.3201/eid1511.090461

3. Figueiredo ML, Figueiredo LTM. Emerging alphaviruses in the Americas. Rev Soc Bras Med Trop. 2014;47:677-83. http://dx.doi.org/10.1590/0037-8682-0246-2014

4. Mourão MP, Bastos Mde S, de Figueiredo RP, Gimaque JB, Galusso Edos S, Kramer VM, et al. Mayaro fever in the city of Manaus, Brazil, 2007-2008. Vector Borne Zoonotic Dis. 2012:42-6. http://dx.doi.org/10.1089/vbz.2011.0669

5. Zuchi N, Heinen LB, Santos MA, Pereira FC, Slhessarenko RD. Molecular detection of Mayaro virus during a dengue outbreak in the state of Mato Grosso, central-west Brazil. Mem Inst Oswaldo Cruz. 2014;109:820-3. http://dx.doi.org/10.1590/0074-0276140108
6. Pauvolid-Corrêa A, Juliano RS, Campos Z, Velez J, Nogueira RM, Komar N. Neutralising antibodies for Mayaro virus in Pamtanal, Brazil. Mem Inst Oswaldo Cruz. 2015;110:125-33.

7. Shope RE. The use of a microhemagglutination-inhibition test to follow antibody response after arthropod-borne virus infection in a community of forest animals. An Microbiol (Rio J). 1963;11 (Pt A):167-71.

8. Kuno G, Gómez I, Gubler DJ. Detecting artificial anti-dengue IgM immune complexes using an enzyme-linked immunosorbent assay. Am J Trop Med Hyg. 1987;36:153-9.

9. Vasconcelos PFC, Travassos Da Rosa JF, Guerreiro SC, Dégallier N, Travassos Da Rosa ES, Travassos Da Rosa AP. First register of an epidemic caused by Oropouche virus in the states of Maranhão and Goiás, Brazil [in Portuguese]. Rev Inst Med Trop Sao Paulo. 1989;31:271-8. http://dx.doi.org/10.1590/ S0036-46651989000400011

10. Figueiredo LTM, Nogueira RMR, Cavalcanti SMB, Schatzmayr H, da Rosa AT. Study of two different enzyme immunoassays for the detection of Mayaro virus antibodies. Mem Inst Oswaldo Cruz. 1989;84:303-7. http://dx.doi.org/10.1590/S0074-02761989000300003

Address for correspondence: Giovanni Rezza, Department of Infectious Diseases, Istituto Superiore di Sanità, Viale Regina Elena 161, 00142 Rome, Italy; email: giovanni.rezza@iss.it

\section{Ebola Virus Imported from Guinea to Senegal, 2014}

\author{
Daye Ka, ${ }^{1}$ Gamou Fall, ${ }^{1}$ Viviane Cissé Diallo, \\ Ousmane Faye, Louise Deguenonvo Fortes, \\ Oumar Faye, Elhadji Ibrahim Bah, \\ Kadia Mbaye Diallo, Fanny Balique, \\ Cheikh Tidiane Ndour, Moussa Seydi, ${ }^{2}$ \\ Amadou Alpha Sall ${ }^{2}$
}

Author affiliations: Centre Hospitalier Universitaire de Fann, Dakar, Senegal (D. Ka, V. Cissé Diallo, L. Deguenonvo Fortes, K.M. Diallo, C.T. Ndour, M. Seydi); Institut Pasteur de Dakar, Dakar (G. Fall, Ousmane Faye, Oumar Faye, F. Balique, A.A. Sall); Hôpital National Donka, Conakry, Guinea (E.I. Bah)

DOI: https://dx.doi.org/10.3201/eid2306.161092

In March 2014, the World Health Organization declared an outbreak of Ebola virus disease in Guinea. In August 2014, a case caused by virus imported from Guinea occurred in Senegal, most likely resulting from nonsecure funerals and travel. Preparedness and surveillance in Senegal probably prevented secondary cases.

\footnotetext{
${ }^{1}$ These authors contributed equally to this article.
}

${ }^{2}$ These authors contributed equally to this article. 